\title{
CARACTERIZAÇÃO DOS COMPLEXOS ORTOGNÁISSICOS ARQUEANOS DE GOIÁS POR GAMAESPECTROMETRIA AÉREA
}

\author{
MARCELO L. B. BLUM', HARDY JOST ${ }^{2}$, ROBERTO A. V. MORAES ${ }^{1}$ \& AUGUSTO C. B. PIRES
}

\begin{abstract}
CHARACTERIZATION OF THE ARCHEAN ORTOGNAISSE COMPLEXES OF GOIÁS BY AIRBORNE GAMMA-RAY SPECTROMETRY The Archean terranes of Goiás, Central Brazil, consist of 5 greenstone belts, and four complexes and one block of orthogneisses. The lithologic similarity among the complexes, inspite of their diferent ages, contribute significantly for their delimitation and interna subdivision during geologic maping. These dificulties may be eliminated by means of quantitatively interpreted aeroradiometric data.
\end{abstract}

Keywords: airborne gamma-ray spectrometry, Goiás Massif, orthogneisses, Archean

\begin{abstract}
Resumo Os terrenos arqueanos de Goiás consistem de cinco faixas de rochas supracrustais do tipo greenstone belt e quatro complexos e um bloco de ortognaisses tonalíticos a granodioríticos, subordinadamente graníticos. A semelhança litológica entre os complexos, a par de suas idades distintas, contribui significativamente para a dificuldade de sua delimitação e subdivisão interna durante mapeamentos geológicos. Estas dificuldades são eliminadas a partir do emprego de dados aeroradiométricos quantitativamente interpretados.
\end{abstract}

Palavras-chave: gamaespectrometria aérea, Maciço de Goiás, gnaisses, Arqueano

\begin{abstract}
INTRODUÇÃO Os terrenos arqueanos de Goiás consistem de típica associação granito-greenstone belt exposta em aproximadamente $50.000 \mathrm{~km}^{2}$. Cerca de $75 \%$ da sua área compreende associações de ortognaisses agrupados em vários complexos, os demais $25 \%$ representados por 5 estreitas faixas de greenstonebelts (Fig. 1). Enquanto maioria das faixas de supracrustais sustenta relevo positivo que propicia o seu mapeamento detalhado, as associações de ortognaisses estão expostas em depressões aplainadas e, apesar dos incipientes perfis de solo, em geral regolitos e litossolos, a individualização dos vários corpos de gnaisses e os limites entre complexos é dificultada pela escassez de afloramentos. Nas últimas duas décadas, grande parte dos terrenos arqueanos foram mapeados na escala 1:25.000. Mesmo assim, o caráter deprimido dos ortognaisses e sua semelhança litológica, apesar de geocronologicamente distintos, dificultaram sobremodo o reconhecimento de suas respectivas extensões, limites mútuos e eventuais subdivisões internas.
\end{abstract}

Durante a década de 1970, a região central do Brasil e abrangendo grande parte do Estado de Goiás e incluindo os terrenos arqueanos, foi alvo de levantamentos aerogeofísicos pelo Projeto Geofísico Brasil-Canadá (PGBC). O projeto abrangeu cerca de $780.000 \mathrm{~km}^{2} \mathrm{e}$ durante o qual foram obtidos dados magnéticos e gamaespectrométricos aerotransportados, acompanhados de levantamentos geofísicos e geoquímicos terrestres. Mediante o reprocessamento, com aplicação de correções, interpolações, homogeneização espacial e micronivelamento de dados gamaespectrométricos do Projeto PGBC, grande parte das dificuldades resultantes de mapeamento foram superadas e ensejaram a releitura de mapas gerados no passado. Assim, o presente artigo visa divulgar os resultados do reprocessamento daqueles dados, estabelecer limites entre complexos e melhor entender sua geometria, com vistas a suportar estudos de detalhe subseqüentes que contribuam para o entendimento da evolução daquele segmento arqueano.

ARCABOUÇO GEOLÓGICO O Maciço de Goiás se situa na porção central da Província Tocantins e é definido por Fuck (1994) como segmentos colisionais brasilianos que envolvem um microcontinente arqueano (Fig. 1). Neste contexto, a maioria das rochas que contornam o bloco arqueano são de idade proterozóica e, localmente, de idade quaternária. A sudoeste o contato é com Ortognaisses do Oeste de Goiás (Pimentel \& Fuck 1992) ou Bloco de Gnaisses Fazenda Nova (Motta-Araújo \& Pimentel 2003), a oeste e noroeste com sedimentos quaternários da Formação Araguaia (Barbosa et al. 1966), a norte com rochas metavulcanosedimentares e ortognaisses do Arco Magmático de Mara Rosa, a nordeste e leste com rochas metassedimentares respectivamente dos grupos Serra da Mesa e Araxá, a sudeste com a Suíte Plutônica Itapuranga (Oliveira 1994) e, a sul, em parte com a Seqüência Anicuns-Itaberai (Barbosa 1987), de natureza metavulcanosedimentar, e, em parte, com rochas metassedimentares atribuídas ao Grupo Araxá.

$\mathrm{O}$ microcontinente arqueano engloba os greenstone belts de Serra de Santa Rita, Faina, Crixás, Guarinos e Pilar de Goiás, separados por complexos de ortognaisses tonalíticos, subordinadamente granodioríticos, mais raramente graníticos. Na metade setentrional dos terrenos arqueanos, Jost et al. (1994a e b) agrupam os ortognaisses em complexos e blocos, de acordo com a natureza dos seus contatos com os greenstone-belts. Assim, complexos

1 - Laboratório de Geofísica Aplicada - Instituto de Geociências - Universidade de Brasília, Brasília, DF, CEP 70919-970, E-mail: mlbblum@unb.br, rmoraes@unb.br, acbpires@unb.br;

2 - Instituto de Geociências - Universidade de Brasília, Brasília, DF, CEP 70919-970, E-mail: hjost@opengate.com.br 
são agrupamentos de gnaisses, cujos limites com as supracrustais não são zonas de cisalhamento, em contraste com os blocos, cujos limites são zonas de cisalhamento de alto ângulo de mergulho. Jost et al. (1998), em base a dados de campo, dividem os terrenos de ortognaisses em cinco complexos denominados, de sul para norte, de Uvá, Caiçara, da Anta, Caiamar e Hidrolina, e um bloco, Moquém.

Genericamente, o conteúdo litológico dos complexos Uvá, Caiçara, da Anta e Caiamar é semelhante, e se caracteriza pelo predomínio de gnaisses tonalíticos, subordinadamente granodioríticos e, ocasionalmente, graníticos. O complexo Hidrolina consiste em mais de $90 \%$ de gnaisses granodioríticos e o Bloco Moquém por proporções semelhantes de gnaisses granodioríticos, graníticos e tonalíticos. Todos contém proporções variadas de intrusões máficas, particularmente diques, localmente stocks e chaminés, mas cujas dimensões não permitem sua detecção mediante os dados de aeroradiometria disponíveis.

PROJETO GEOFÍSICO BRASIL - CANADÁ O Projeto Geofísico Brasil-Canadá (PGBC) resultou de acordo entre o Governo do Brasil e a Agência Canadense para o Desenvolvimento Internacional (CIDA) com vistas à execução do levantamento dos recursos minerais da região Centro-Oeste do Brasil. O
Departamento Nacional de Produção Mineral (DNPM) iniciou o PGBC em 1975, com cobertura da área situada entre $5^{\circ} \mathrm{S}$ e $16^{\circ} \mathrm{S}$ e $48^{\circ} \mathrm{W}$ e $51^{\circ} \mathrm{W}$. Os levantamentos foram aerotransportados e consistiram na obtenção de dados de magnetometria, espectrometria gama e eletromagnetometria no domínio do tempo - INPUT, apoiados por levantamentos terrestres, com coleta de sedimentos de corrente para determinações geoquímicas e perfilagem magnetométrica em áreas selecionadas (DNPM 1981).

Durante o levantamento aéreo foram utilizadas aeronaves DC-3, com deslocamento aproximado de $220 \mathrm{~km} / \mathrm{h}$, a $150 \mathrm{~m}$ de altura com tolerâncias de $\pm 10 \%$ (topografia suave) e de $\pm 50 \%$ (em regiões acidentadas). $\mathrm{O}$ controle da altura realizou-se por meio de radar altímetro, com leitura a cada segundo. O controle de navegação foi realizado mediante sistema de navegação Doppler e recuperado a partir de fotografias colhidas durante o vôo com câmeras de 35 $\mathrm{mm}$. As linhas de produção e controle foram voadas segundo NS, com espaçamento de $2 \mathrm{~km}$, e na direção $\mathrm{EW}$, com espaçamento de $14 \mathrm{~km}$. Linhas de produção com vistas ao detalhamento foram inseridas a cada $1 \mathrm{~km}$ em áreas selecionadas em etapa posterior (DNPM 1981). A aquisição de dados gamaespectrométricos foi realizada com espectrômetro diferencial equipado com detetores de Iodeto de Sódio ativados com Tálio [NaI(Tl)], com amostragem das janelas do espectro correspondentes aos da energia de

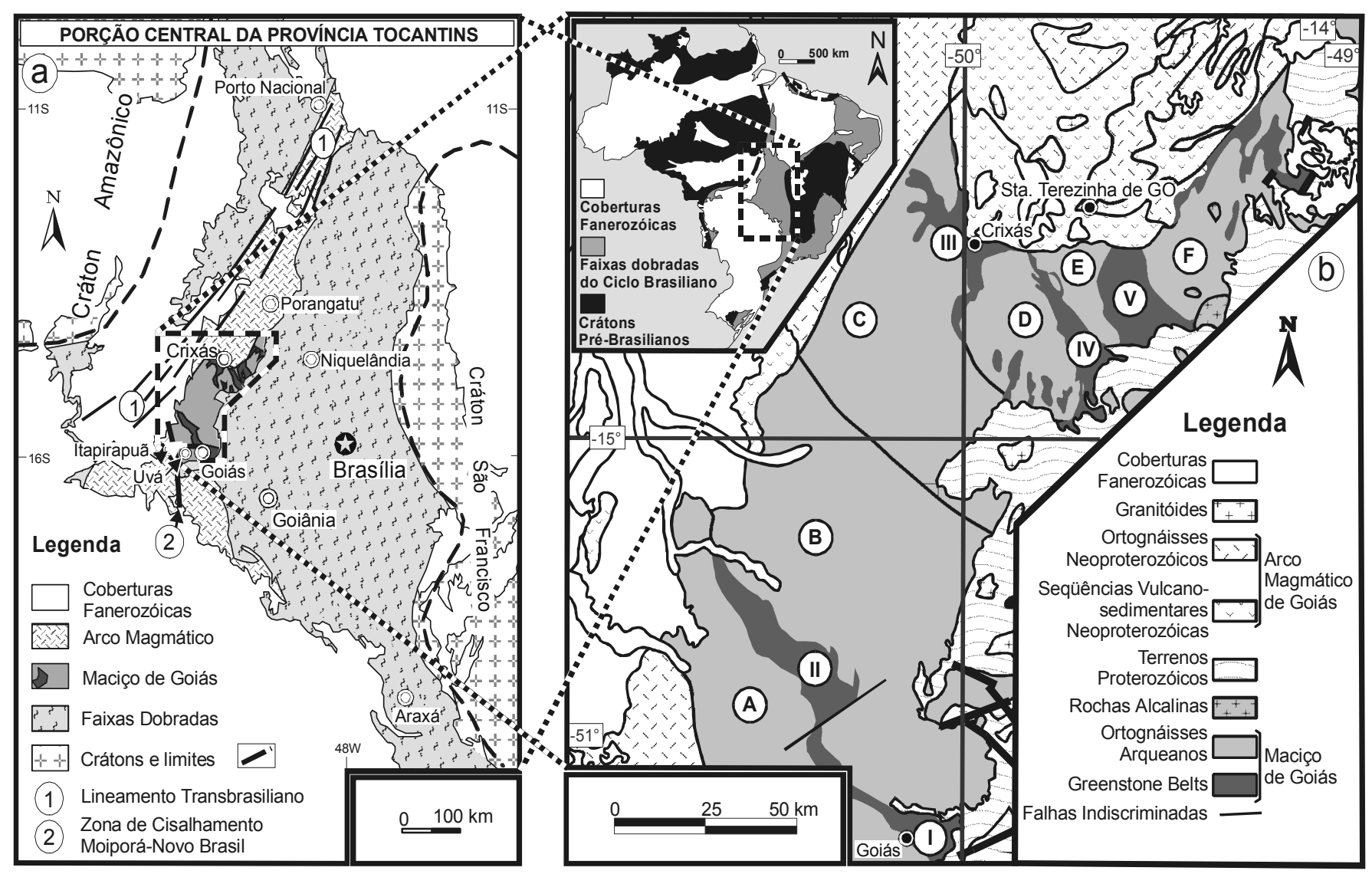

Figura 1 - a) Principais compartimentos da porção central da Província Tocantins (Fuck 1994, Blum 1999, modificado). b) Mapa geológico simplificado da área estudada (compilado por Blum 1999 e baseado em DNPM 1987, Jost \& Oliveira 1991, Fuck 1994, Lacerda 1997, Resende et al. 1998, Jost et al. 1998). (1) Arco Magmático; (2) Maciço de Goiás. Blocos/complexos gnáissicos: (A) Uvá; (B) Caiçara; (C) da Anta; (D) Caiamar; (E) Moquém; (F) Hidrolina. Greenstone Belts: (I) Serra de Santa Rita; (II) Faina; (III) Críxás; (IV) Guarinos; (V) Pilar de Goiás. 
contagem total $(0,4-2,81 \mathrm{MeV})$, Potássio (1,37-1,57 MeV), Urânio $(1,66-1,86 \mathrm{MeV})$ e Tório $(2,41-2,81 \mathrm{MeV})$, com registro contínuo em contagem por segundo (cps).

PROCESSAMENTODOSDADOS AEROGAMAESPECTROMÉTRICOS O processamento dos dados gamaespectrométricos realizou-se no Laboratório de Geofísica Aplicada (LGA) do Instituto de Geociências da Universidade de Brasília, em meio digital e com o emprego do programa GEOSOFT Inc., OASIS MontajÔ (GEOSOFT 1996, 1998). A primeira abordagem dos dados incluiu a avaliação da presença de inconsistências, tais como o efeito pepita e picos destituídos de significado local, e da distribuição espacial das linhas de vôo. Dados relativos a inconsistências maiores foram excluídos e o padrão geral das linhas de vôo ofereceu problemas significativos, exceto os decorrentes de eventuais desvios de registro de rota devido ao sistema precário de posicionamento disponível na época. Os dados originais foram interpolados em malhas regulares construídas pelos métodos de curvatura mínima e bidirecional. O tamanho da célula unitária quadrada foi de $500 \mathrm{~m}$, atendendo, assim, o maior espaçamento entre as linhas de vôo de $2000 \mathrm{~m}$. Entre os métodos, o bidirecional apresentou a melhor preservação das mais importantes altas freqüências.

$\mathrm{O}$ nivelamento convencional dos dados aerogamaespectrométricos, com o emprego de linhas de vôo transversais às de medida, sempre resulta em algumas imperfeições na representação espacial dos dados. Para minimizá-los, empregou-se o micronivelamento (Minty 1991), com algoritmo desenvolvido por Blum (1999). A partir destas malhas foram geradas imagens digitais com emprego de técnicas de sombreamento e composição em falsa cor em padrão RGB.

\section{INTERPRETAĈ̃OAEROGAMAESPECTROMÉTRICA A}

interpretação dos dados gamaespectrométricos dos complexos granito-gnáissicos arqueanos da região realizou-se a partir de imagens coloridas dos canais individuais do urânio (U), tório (Th), potássio (K) e de contagem total (CT) (Figs. 2a, b, c e d) e da imagem ternária dos canais do U, Th e K combinados (Fig. 2e). Na última, entre as combinações que apresentou os melhores resultados foi o padrão de cores $\mathrm{RGB}$, com o $\mathrm{K}$ em vermelho (R), o Th em verde (G) e o U em azul (B).

O limite ocidental do bloco arqueano com os Gnaisses do Oeste de Goiás e da Formação Araguaia pode ser traçado mediante a análise combinada dos canais do K, Th, U e CT e da composição ternária K-Th-U, pois os complexos granito-gnáissicos respondem radiometricamente de forma diversa. Por outro lado, no limite oriental, apenas as rochas metassedimentares do Grupo Serra da Mesa, no extremo nordeste, e metavulcano-sedimentares da Seqüência Anicuns-Itaberai podem ser distinguidas por seus baixos valores nos canais do $\mathrm{K}$ e do $\mathrm{Th}$ e $\mathrm{CT}$, respectivamente. Contudo, o limite oriental dos terrenos arqueanos com as unidades mais jovens é bem evidente na composição ternária K-Th-U (Fig. 2e), devido à variação da resposta radiométrica de todas unidades. Por seu turno, o limite do bloco com o Arco Magmático de Goiás, no norte, pode ser traçado mediante a análise combinada das respostas nos canais do Th, $\mathrm{U}$ e $\mathrm{CT}$, mas é mais proeminente na composição ternária K-Th-U.

Internamente ao bloco arqueano, dependendo do canal, as faixas de greenstone belts podem ser distinguidas dos complexos granitognáissicos. Contudo, como o objeto do artigo são as diferenças entre os complexos granito-gnáissicos, as assinaturas das faixas de supracrustais arqueanas não serão discutidas, motivo pelo qual estão, na figura 2, representados em preto. Nos parágrafos que seguem, as propriedades radiométricas dos complexos e suas diferenças serão apresentadas mediante a comparação entre segmentos contíguos, de sudoeste para nordeste.

O Complexo Uvá, situado no extremo sul da área (A na Fig. 2e), está separado do Complexo Caiçara (B na Fig. 2e) pelos greenstone belts de Serra de Santa Rita e Faina (I e II na Fig. 2e). Dados de campo e petrográficos de ambos complexos registram que, apesar de litologicamente semelhantes, o Complexo Uvá difere do Complexo Caiçara pelos baixos valores nos canais do K, Th, CT e de combinação ternária K-Th-U. Em ambos, é possível distinguir detalhes que correspondem a fatos geológicos. No Complexo Uvá, o limite com os gnaisses do Este de Goiás é a proeminente Zona de Cisalhamento Moiporá-Novo Brasil, a qual aloja stocks de granitos. A intrusão maior e algumas menores das proximidades, se destacam na composição ternária $\mathrm{K}-\mathrm{Th}-\mathrm{U}$ pela mancha vermelha situada próximo do limite noroeste do mesmo. Por outro lado, no extremo nordeste do Complexo Uvá, junto à cidade de Goiás, há um corpo de tonalito que se destaca pelos altos valores nos canais do $\mathrm{K}$ e composição ternária e valores moderados no canal do Th. Já no Complexo Caiçara, a porção sudeste difere do restante pelos baixos valores nos canais do K e CT e que, no extremo sudeste, corresponde a uma intrusão trondhjemítica neoproterozóica (Pimentel et al.2003) e, no extremo noroeste, a gnaisses tonalitos. $\mathrm{Na}$ imagem de composição ternária, a variação de assinaturas do Complexo Caiçara resulta da diversidade composicional de corpos de gnaisses tonalíticos., em cuja porção central são mais ricos em biotita que os situados a oeste e leste.

Para norte, os Complexo Caiçara (B na Fig. 2e) e da Anta (C na Fig. 2e) estão em contato quase linear situado ao longo do canal do Rio Tesouras. Ambos complexos não diferem nas assinaturas dos canais do K, Th e CT, mas o Complexo da Anta se destaca pelas leituras discretamente maiores no canal do U. Contudo, na imagem de composição ternária, a diferença entre ambos complexos é substancial e que resulta da combinação de valores distintos nos três canais, com valores mais elevados registrados no Complexo da anta, comparativamente ao Complexo Caiçara, onde o registro no canal do U é significativamente menor.

Por outro lado, as diferenças entre os Complexos da Anta ( $\mathrm{C}$ na Fig. 2e) e Caiamar (D na Fig. 2e), situado imediatamente a leste, são proeminentes devido aos valores significativamente menores do último nos canais do Th, U, CT e composição ternária. No detalhe, é possível distinguir a subdivisão interna do Complexo Caiamar nas três unidades propostas por Jost et al. (1994b). Assim, no canal do K, a área triangular situada no extremo norte corresponde aos Gnaisses Crixás Açu, de composição tonalítica e que difere do Tonalito Tocambira situado imediatamente a sul. Já nos canais do Th, CT e composição ternária, os Gnaisses Águas Claras, de composição granodiorítica, são realçados pelos valores maiores, comparativamente ao Tonalito Tocambira, situado imediatamente a norte. Apesar da ausência de contraste entre os Gnaisses Águas Claras e os do limite sudeste do Complexo da Anta nos canais do $\mathrm{K}$, Th e CT, estes diferem discretamente no canal do $\mathrm{U}$ e na composição ternária.

O Bloco do Moquém (E na Fig. 2e), situado entre os greenstone belts de Guarinos e Pilar de Goiás (IV e V na Figura 2e), consiste de gnaisses graníticos no sul e sudoeste, granodioríticos a noroeste e norte e tonalíticos no leste, localmente migmatitos, diques anfibolitizados e um stock tonalítico (Jost et al. 1998). O bloco não se distingue dos demais complexos no canal do $\mathrm{K}$, mas é distinto nos canais do Th e, em detalhes, nos canais do U e CT. 


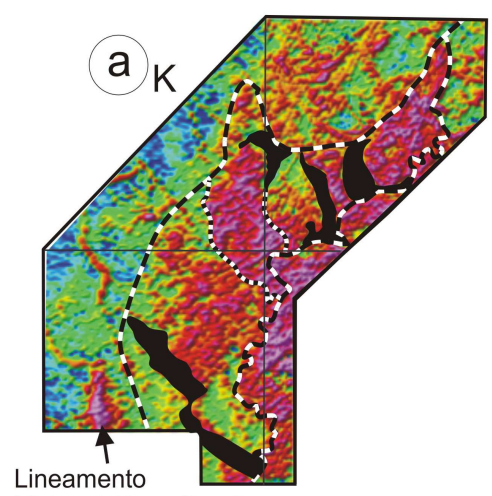

Lineamento

Moiporá-Novo Brasil

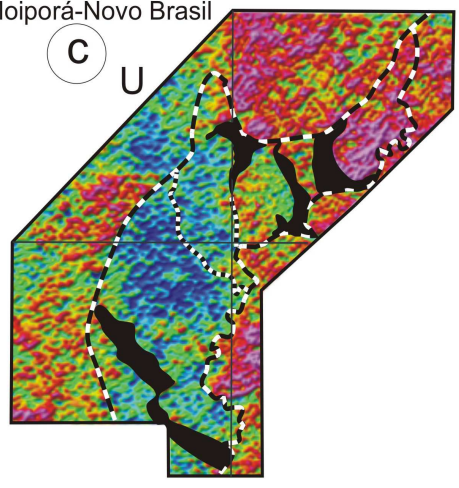

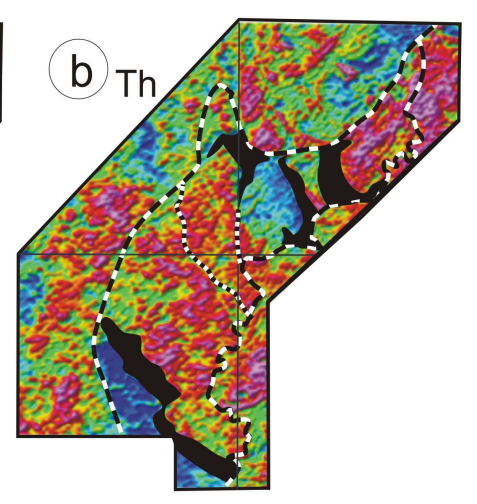

(d) CT

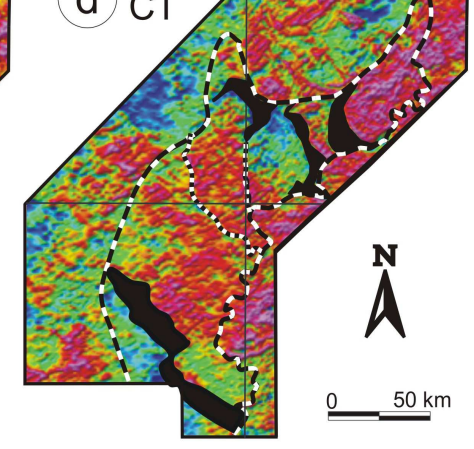

Legenda

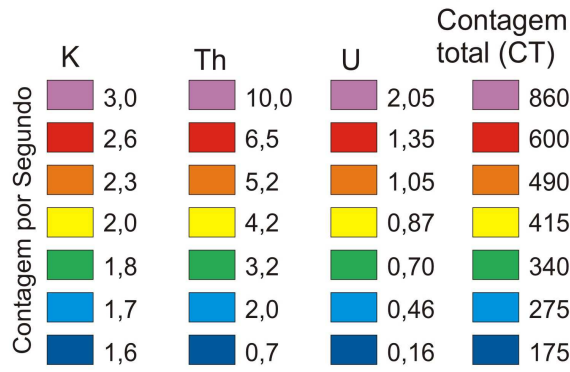

Limite dos terrenos $\because$ arqueanos

Limite dos complexos $\because$ de ortognaisses

Greenstone belts

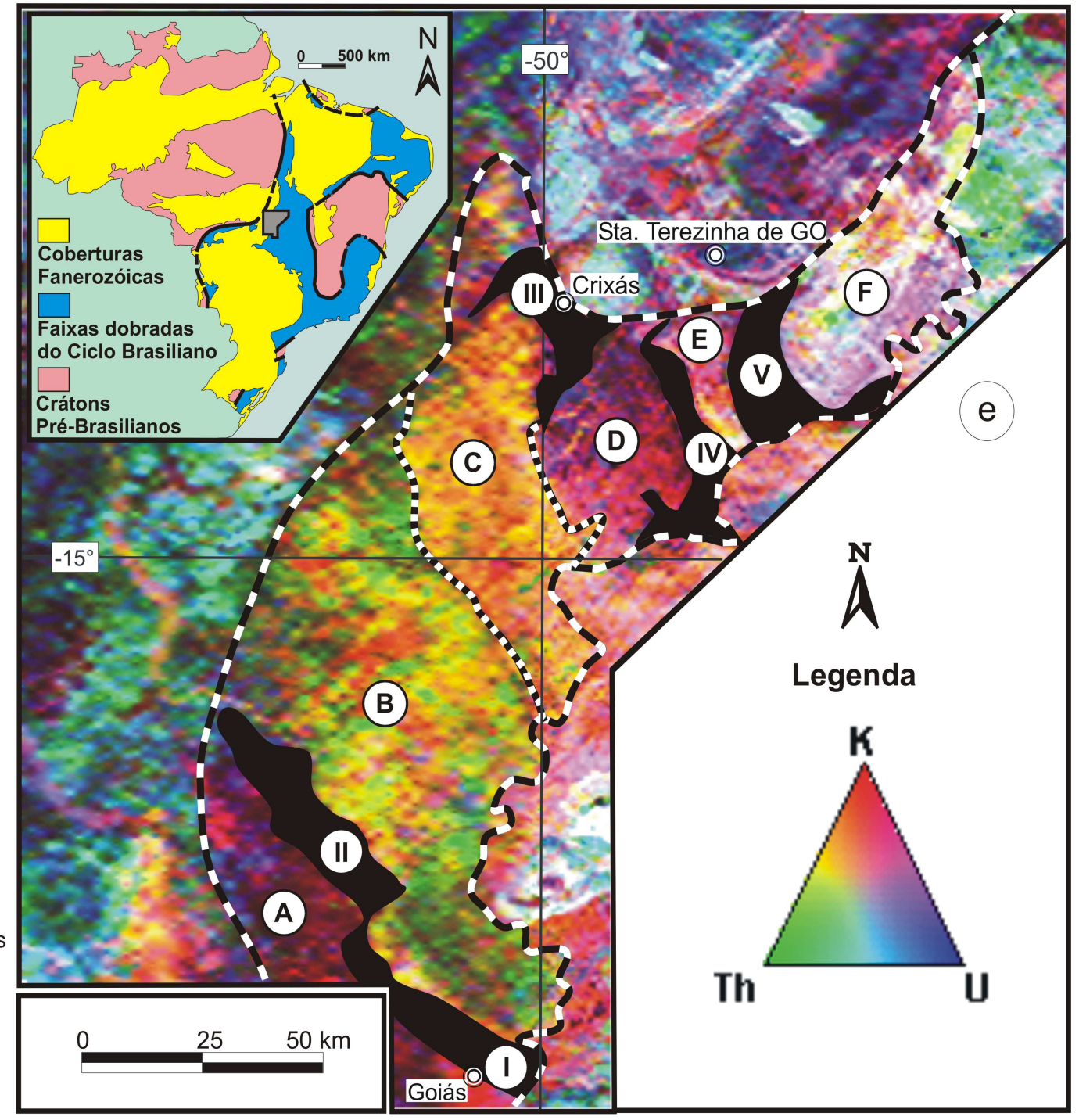

Figura 2 - Imagens coloridas de aerogamaespectrometria dos complexos granito-gnáissicos arqueanos de Goiás. (a) canal do potássio, (b) canal do tório, (c) canal do urânio, (d) contagem total e (e) Imagem ternária RGB de K, The U. Legenda da figura 2e: Complexos granito-gnáissicos = (A) Uvá; (B) Caiçara; (C) da Anta; (D) Caiamar, (E) Moquém; (F) Hidrolina. Greenstone belts: (I) Serra de Santa Rita, (II) Faina, (III) Crixás, (IV) Guarinos e (V) Pilar de Goiás. 
Internamente, no entanto, a distribuição dos os principais grupos de gnaisses apresentam assinaturas distintas, pois no canal do Th, os gnaisses graníticos de sudoeste e sul estão claramente delimitados dos demais, enquanto o canal do $U$ define a área de ocorrência de gnaisses tonalíticos de leste. Por outro lado, a composição ternária novamente distingue a área de ocorrência dos três principais tipos composicionais de gnaisses.

A leste do greenstone belt de Pilar de Goiás (V na Figura 2e) situa-se o Complexo de Hidrolina (F na Figura 2e), composto de gnaisses granodioríticos. No canal do $\mathrm{K}$, este complexo não se distingue dos demais. Contudo, este segmento se distingue do Bloco Moquém e do complexo Caiamar pelos altos valores no canal do Th, de todos os demais no canal do U e, no de CT apenas do Complexo Caiamar e parte do Bloco Moquém. Já na imagem ternária, este complexo difere significativamente dos demais pela maior combinação dos três canais. Por outro lado, na mesma imagem, há uma clara variação entre as bordas sul e leste do complexo, mais foliadas por cisalhamento, comparativamente à porção norte-noroeste, textualmente mais preservada.

CONCLUSÕES O emprego da interpretação qualitativa de dados aerogamaespectrométricos foi ferramenta fundamental no traçado dos limites entre complexos granito-gnáissicos arqueanos de Goiás e as informações assim obtidas estimularam a revisão de campo destes limites, a rigor desconhecidos nos trechos não obliterados por greenstone belts. Da mesma forma, os dados gamaespectrométricos corroboraram subdivisões internas reconhecidas em trabalhos anteriores, tais como as do Bloco Moquém e do Complexo Caiamar, e a heterogeneidade interna do Complexo Hidrolina condicionada pelo cisalhamento periférico. Por outro lado, os dados também estimularam a investigação mais detalhada, em curso, das razões de heterogeneidades radiométricas internas dos complexos da Anta, Caiçara e Uvá. Cumpre ressaltar que, apesar das semelhanças litológicas entre os complexos e entre estes e o Bloco Moquém, às diferenças radiométricas se somam distintas idades U-Pb em zircão, como registrado por Queiroz (2000) na metade setentrional e por (Jost et al. 2003, em preparação) na metade meridional do bloco arqueano. As diferenças aqui registradas certamente contribuirão para um melhor entendimento da geometria interna e evolução do segmento arqueano de Goiás.

Agradecimentos À CPRM e ao DNPM pelos dados aaeeroradiométricos do $\mathrm{PGBC}$ e apoio. Aos revisores da RBG pelas sugestões ao manuscrito.

\section{Referências}

Barbosa et al. 1966. Geologia estratigráfica, estrutural e econômica da área do Projeto Araguaia. DNPM, Divisão de Geologia e Mineralogia, Rio de Janeiro, Monografia 19, 94 pp.

Barbosa P.A.R. 1987. Geologia e recursos minerais a leste de Mossâmedes, GO. Dissertação de Mestrado, Instituto de Geociências, Universidade de Brasília, 226 pp.

Blum M.L.B. 1999. Processamento e interpretação de dados de geofisica aérea no Brasil Central e sua aplicação à geologia regional e à prospecção mineral. Instituto de Geociências, Universidade de Brasília, Brasília, Tese de Doutoramento, 229p.

DNPM 1981. Projeto Geofísico Brasil-Canadá: histórico e atividades até 30/09/77. MME/DNPM, GSC.

DNPM 1987. Mapa Geológico do Estado de Goiás (Escala 1:1.000.000). DNPM/MME, Brasília.

Fuck R.A. 1994. A Faixa Brasília e a compartimentação tectônica na Província Tocantins. In: SBG, Simp. Geol. Centro-Oeste, 4, Brasília, Anais, p. 184-187.

GEOSOFT 1996. MAGMAP 2-D frequency domain processing. GEOSOFT, Inc., Toronto.

GEOSOFT 1998. OASIS Montaj 4.2. GEOSOFT, Inc., Toronto.

Jost H. \& Oliveira A.M. 1991. Stratigraphy of the greenstone belts, Crixás region, Goiás, central Brazil. J. South Am. Earth Sci., 4:201214.

Jost H., Vargas M.C., Fuck R.A., Kuyumjian R.M., Pires A.C.B. 1994a. Relações de contato, litologias, geologia estrutural e geofísica do Bloco Arqueano do Moquém, Crixás, Goiás. SBG, Simpósio de Geologia do Centro-Oeste, IV, Brasília, Resumos Expandidos, p. 15-17.

Jost H., Carmelo A.C., Meneses P.R. 1994b. Litologias, relações de contato e estrutura do Bloco Caiamar, Crixás, Goiás. In: SBG, Simp. Geol. Centro-Oeste, 4, Brasília, Anais, p. 18-20.

Jost H., Resende M.G., Osborne G.A., Queiroz C.L., Blum M.L.B., Pires A.C.B., Moraes R.A.V. 1998. O Arqueano do Estado de Goiás. (inédito)

Lacerda H. 1997. Mapa Geológico do Greenstone Belt Crixás-Pilar de Goiás. CPRM, (inédito).

Minty, B.R.S. 1991. Simple micro-levelling for aeromagnetic data. Expl. Geoph., 22:591-592.

Motta-Araújo J.G. \& Pimentel M.M. 2003. U-Pb ages, Sm-Nd isotopes and structural analysis of the Moiporá-Novo Brasil shear sone system: the limits between the Neoproterozoic Goiás Magmatic Arc and the Archean Uvá Complex, Tocantins Province, Central Brazil. In: South Am. Symp. Isotope Geology, 4, Salvador, Bahia, Short Papers, 1:221-224

Oliveira C.C. 1994. Programa Levantamentos Geológicos Básicos PLGB-Folha SE-22-X-B-V-Leopoldo Bulhões. Esala 1:100.000. CPRM/DNPM, Goiânia, 151 pp.

Pimentel M.M. \& Fuck R.A. 1992. Características geoquímicas e isotópicas de unidades metavulcânicas e ortognáissicas neoproterozóicas do oeste de Goiás. SBG, Núcleo Centro-Oeste, Boletim, $\mathrm{n}^{\circ} 15,1-22$ 
Queiroz, C.L., 2000.Evolução tectono-estrutural dos terrenos granitotreenstone belt de Crixás, Brasil Central. Instituto de Geociências, Universidade de Brasília, Tese de Doutorado, 209p.

Resende M.G., Jost H., Osborne G.A., Mol A.G. 1998. Stratigraphy of the Goiás and Faina greenstone belts, Central Brasil: a new proposal. Rev. Bras. Geoc. 28:77-94.

Manuscrito SR-19

Recebido em08 de outubro de 2002

Revisão dos autores em10 de março de 2003

Revisão aceita em 20 de abril de 2003 